\title{
Posterior mediastinal neuroblastoma in an infant presenting with paraparesis: a case report
}

\author{
Rajparath $\mathbf{R}^{*}$, Rangesh $\mathrm{S}^{* *}$, Senthamarai $M \mathbf{V}^{* * *}$ \\ *Post graduate, ${ }^{* *}$ Assistant Professor and ${ }^{* * *}$ HOD and Professor, Department of Pediatrics, Vinayaka Mission's \\ Kirupananda Variyar Medical College and Hospital, Salem, Tamilnadu, India.
}

Address for Correspondence: Rajparath R, Email: rajragu89@gmail.com

\begin{abstract}
Neuroblastoma is the third most common malignancy in childhood and it is the most common intraabdominal tumour of the children. There are varied clinical presentations of this tumour depending upon the location of the tumour. Primary mediastinal neuroblastoma accounts for nearly $14 \%$ and they often present with respiratory symptoms. In this case report, we describe a case of neuroblastoma in a 11 months old Infant, located in the Posterior mediastinum presenting with Paraparesis. We present this case for its unique presentation for the age and location of the primary tumour.
\end{abstract}

Key words: Neuroblastoma, Infant, Posterior mediastinum, Paraparesis

\section{Introduction}

Neuroblastomas are embryonal cancers of the peripheral sympathetic nervous system. It accounts for about $8-10 \%$ of childhood malignancy and one third of cancers in infants [1]. Primary mediastinal neuroblastoma accounts nearly $14 \%$, but they have often presented with respiratory symptoms [2]. An infant with posterior mediastinal neuroblastoma presenting with paraplegia is a rare entity and never been documented.

\section{Case report}

A 11 month old, developmentally normal, male infant born of non-consanguinous marriage presented with irritability and difficulty in standing and sitting for 1 week. On examination the child had irritability, no cranial nerve palsy, normal tone and power in upper limbs, hypotonia in both lower limbs.

Child was able to move the both lower limbs after eliminating the gravity but not able to raise both lower limbs against gravity (Power 2/5). Superficial reflexes were absent and deep tendon reflexes being sluggish.

Examination of other systems was unremarkable. On consecutive days of evaluation, the child had persistent hypotonia and diminished power in both lower limbs, superficial reflexes remained absent but the deep tendon reflexes gradually started to become brisk.

USG Abdomen was normal and Chest X - ray AP and Lateral view were done, showed mediastinal widening (FIG 1, 2), Stool culture for Poliovirus was negative. CT Spine showed large homogenous mass in the posterior mediastinum with punctate calcification in the hypodense mass. Later MRI spine was taken, which revealed a large homogenous mass located in the posterior mediastinum and left hemithorax with intraspinal extension (FIG 3). Following which urine VMA level was done which was elevated. Histopathology of the tumour showed poorly differentiated neuroblastoma which later confirmed the diagnosis. Bone marrow showed normal study Child was started on chemotherapy and on regular follow-up.

Manuscript received: $15^{\text {th }}$ August 2016

Reviewed: $28^{\text {th }}$ August 2016

Author Corrected; $12^{\text {th }}$ September 2016

Accepted for Publication: $25^{\text {th }}$ September 2016 


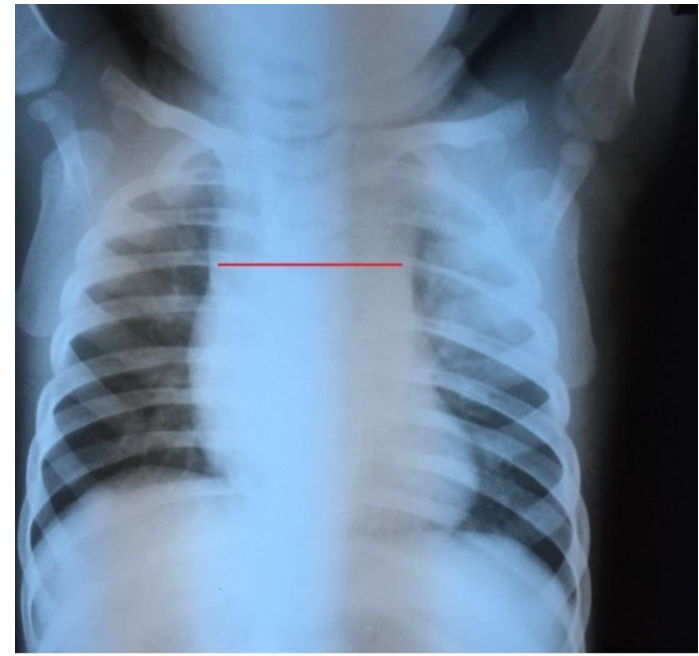

FIGURE 1 : CHEST XRAY AP VIEW SHOWING MEDIASTINAL WIDENING

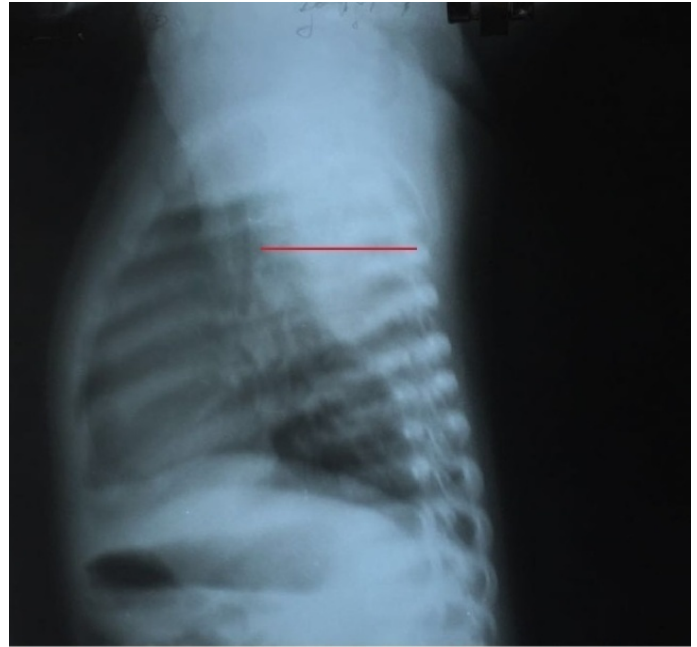

FIGURE 2 :CHEST XRAY LATERAL VIEW SHOWING MEDIASTINAL WIDENING AND HOMOGENOUS MASS IN POSTERIOR MEDIASTINUM

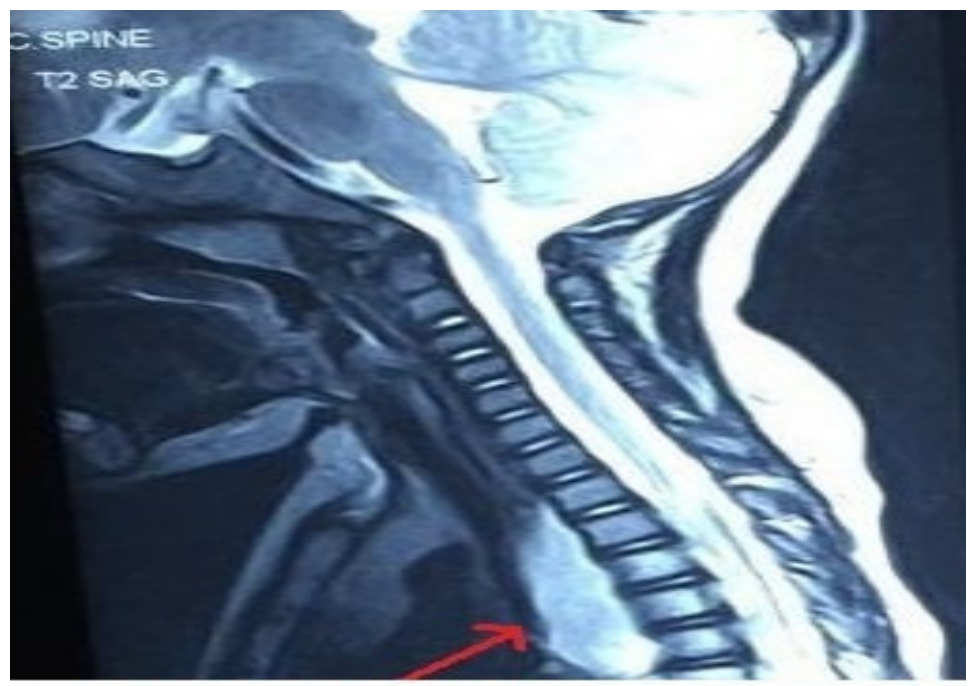

FIGURE 3:MRI IMLAING SHOWING MLASS IN THE POSTERIOR MIEDIASTINUM

\section{Discussion}

Neuroblastoma is the third commonest malignant tumour of childhood. Neuroblastoma is the most common malignancy in infancy. $90 \%$ of cases are diagnosed in children $<5$ years of age ${ }^{1}$. Peak incidence is $2-3$ years $^{3,4}$. Posterior mediastinal neuroblastoma is nearly seen in $20 \%$ of cases ${ }^{5}$. They are often located primarily in the adrenals (35\%). Other sites of occurrence include paraspinal ganglia $(30 \%)$, pelvis $(2-3 \%)$, neck (1-5\%), unusual tumours are also seen in thymus, lung, kidney, stomach, cauda equina. Most thoracic neuroblastomas often present with symptoms depending on the site. The presenting symptoms in case of thoracic neuroblastoma may include airway obstruction and chronic cough. Sometimes may present with weakness, limping, paralysis and bladder and bowel disturbances if the tumour is seen in para spinal sympathetic ganglia. Metastatic disease often manifests as unexplained fever, weight loss, irritability, bone pain and fractures in cases of bone metastases ${ }^{4}$. As in this case, posterior mediastinal neuroblastoma presenting with paraparesis is uncommon. Often the disease is diagnosed incidentally as in this case in which mediastinal widening in the chest $\mathrm{x}$-ray raised the suspicion of posterior mediastinal mass. Nearly $90 \%$ of cases have raised VMA (Vanillylmandelic acid) levels and HVA (homovanillic acid) in urine ${ }^{6}$. Imaging studies include CT which often shows the location, extent to the adjacent organ involvement and vascularity, it often demonstrates calcifications in $90 \%$ of cases $^{7,8}$. MRI is the imaging of choice for better delineation of full 
extent of mass, extradural/intra-spinal extension and chest wall invasion ${ }^{8,9}$. Often the disease is confirmed by biopsy of the tumour. Treatment modalities include surgery, chemotherapy and radiotherapy which is planned according to the age, stage, histology of the tumour, gene studies (MYCN) and DNA ploidy ${ }^{10}$. Staging of the disease are done based on international neuroblastoma staging system (INSS). Children less than 1 year of age have good prognosis, i.e. $80-90 \%$ survival rate after 5 years, but those with spinal cord compression as in this case need urgent chemotherapy, surgery and radiation to prevent neurological damage ${ }^{1}$. Follow-up of the patients is always necessary to check for their response to treatment and detect recurrence. Urine catecholamine levels are checked on every visit. Repeat imaging studies are also done at frequent intervals.Most recurrences are said to occur within first 2 years of treatment and patients who remain free of recurrence for a period of 5 years are said to be cured of the disease $\mathrm{e}^{11,12}$.

\section{Conclusion}

Primary posterior neuroblastoma presenting with paraparesis in infants is uncommon. However, prognosis of neuroblastoma in infancy is good. So, strong clinical suspicion may hasten the diagnosis, treatment and recovery.

\section{Funding: Nil, Conflict of interest: Nil \\ Permission from IRB: Yes}

\section{References}

1. Robert M Kleigman. Nelson textbook of pediatrics. $20^{\text {th }}$ ed. Elsevier. 2015.

2. Gupta AK, Manjunatha YC. Imaging in mediastinal neuroblastoma. Indian J Pediatr. 2010 Jan;77(1):105-6. doi: 10.1007/s12098-010-0003-7.

3. Maris JM, Hogarty MD, Bagatell R, Cohn SL. Neuroblastoma. Lancet. 2007 Jun 23;369(9579):210620.
4. Castleberry RP. Neuroblastoma. Eur J Cancer. 1997 Aug;33(9):1430-7; discussion 1437-8.

5. Papaioannou G, McHugh K. Neuroblastoma in childhood: review and radiological findings. Cancer Imaging. 2005 Sep 30;5:116-27.

6. Park JR-HematolOncolClin North Am-01-FEB2010;24(1):65-86.

7. David R, Lamki N, Fan S, Singleton EB, Eftekhari F, Shirkhoda A, Kumar R, Madewell JE. The many faces of neuroblastoma. Radiographics.1989 Sep;9(5):859-82.

8. Castellote A, Vázquez E, Vera J, Piqueras J, Lucaya J, Garcia-Peña P, Jiménez JA. Cervicothoracic lesions in infants and children. Radiographics. 1999 May-Jun; 19 (3):583-600.

9. Kawashima A, Fishman EK, Kuhlman JE, Nixon MS. CT of posterior mediastinal masses. Radiographics. 1991 Nov;11(6):1045-67.

10. Schulte JH, Horn S, Otto T, Samans B, Heukamp LC, Eilers UC, Krause M, Astrahantseff K, KleinHitpass L, Buettner R, Schramm A, Christiansen H, Eilers M, Eggert A, Berwanger B. MYCN regulates oncogenic MicroRNAs in neuroblastoma. Int J Cancer. 2008 Feb 1;122(3):699-704.

11. Schulte JH, Horn S, Otto T, Samans B, Heukamp LC, Eilers UC, Krause M, Astrahantseff K, KleinHitpass L, Buettner R, Schramm A, Christiansen H, Eilers M, Eggert A, Berwanger B. MYCN regulates oncogenic MicroRNAs in neuroblastoma. Int J Cancer. 2008 Feb 1;122(3):699-704.

12. Brodeur GM, Pritchard J, Berthold F, Carlsen NL, Castel V, Castelberry RP, De Bernardi B, Evans AE, Favrot M, Hedborg F, et al. Revisions of the international criteria for neuroblastoma diagnosis, staging, and response to treatment. J Clin Oncol. 1993 Aug;11(8):1466-77.

\section{How to cite this article?}

Rajparath R, Rangesh S, Senthamarai M V. Posterior mediastinal neuroblastoma in an infant presenting with paraparesis: a case report. Int. J Pediatr Res. 2016;3(9):715-717.doi:10.17511/ijpr.2016.i09.16. 